\title{
HISTÓRIA E MEMÓRIA: a doutrina de segurança nacional e a cultura escolar da Escola Técnica Federal do Rio Grande do Norte (1968-1985)
}

\author{
Aline Cristina da Silva Lima \\ Olívia Morais de Medeiros Neta²
}

\section{RESUMO}

No âmbito educacional, a ideologia da Ditadura, por meio da Doutrina de Segurança Nacional, foi um forte mecanismo de legitimação dos governos militares reverberando em reformas de todas as modalidades e níveis. Especificamente no caso da Educação Profissional, houve mudanças no currículo e acentuação, na rotina escolar, de regras, horários e disciplinamento. Além da forte aproximação com o modelo tecnicista que imprimia uma atmosfera de empresa à escola. Nosso objetivo neste artigo é realizar uma discussão teórica acerca da história oral e memória relacionada a cultura escolar da Escola Técnica Federal do Rio Grande do Norte-ETFRN (1968-1985), durante a Ditadura Militar. Dialogamos com Maurice Halbwachs, Michael Pollack e Ecléia Bosi, no que se refere a noção de memória, esquecimento e silêncio. E, no caso da história oral, as obras de Verena Alberti, Sebe Bom Meihy e Suzana Ribeiro, Alessandro Portelli, Ana Maria Mauad, nos deram as bases para a compreensão dos usos da história oral como arte da escuta e integrada aos novos tempos, ao fazer registros não só auditivos, mas também visuais/imagéticos. Associado a oralidade usaremos também outras fontes: escritas e visuais, como jornais da época, fotografias, diários de classe, currículos e etc. Consideramos que não há uma realidade unívoca, a mesma escola que regulava e disciplinava era a que, por meio de vivências múltiplas construía sujeitos críticos e capazes de ir além do saber fazer.

Palavras-chave: História oral. Memória. Ditadura militar. Doutrina de segurança nacional.

\section{HISTORY AND MEMORY: the national security doctrine and school culture of the Federal Technical School of Rio Grande do Norte (1968-1985)}

\footnotetext{
Doutoranda do Programa de Pós-Graduação em Educação (PPGED/UFRN), Natal, RN, Brasil. Orcid iD: https://orcid.org/0000-0001-7951-0537.E-mail: aline.prof.his@gmail.com

2 Doutora em Educação pela Universidade Federal do Rio Grande do Norte. Professora do Centro de Educação da Universidade Federal do Rio Grande do Norte, no Programa de PósGraduação em Educação (UFRN) e no Programa de Pós-Graduação em Educação Profissional do Instituto Federal de Educação, Ciência e Tecnologia do Rio Grande do Norte (IFRN), Natal, RN, Brasil. Orcid iD: https://orcid.org/0000-0002-4217-2914. E-mail: olivianeta@gmail.com
} 


\section{ABSTRACT}

In the educational field, the dictatorship's ideology, through the Doctrine of National Security, was a strong mechanism for legitimizing military governments, reverberating in reforms at all levels and modalities. Specifically, in the case of Professional Education, there were changes in the curriculum and accentuation, in the school routine, of rules, schedules and discipline, in addition to the strong approach to the technical model that gave the school a business atmosphere. Our aim in this article is to carry out a theoretical discussion about oral history and memory related to school culture at the Federal Technical School of Rio Grande do Norte - ETFRN (1968-1985), during the Military Dictatorship. We interacted with Maurice Halbwachs, Michael Pollack and Ecléia Bosi, regarding the notion of memory, forgetfulness and silence. And, in the case of oral history, the works of Verena Alberti, Sebe Bom Meihy and Suzana Ribeiro, Alessandro Portelli, Ana Maria Mauad, gave us the basis for understanding the uses of oral history as an art of listening and integrated to the new times, making records not only auditory, but also visual / imagery. Associated with orality we will also use other sources: written and visual, such as newspapers of the time, photographs, class diaries, curriculum etc. We believe that there is no univocal reality, the same school that regulated and disciplined was the one that, through multiple experiences, built critical subjects capable of going beyond knowing how to do.

Keywords: Oral History. Memory. Military dictatorship. National Security Doctrine.

\section{HISTORIA Y MEMORIA: la doctrina de seguridad nacional y la cultura escolar de Escuela Técnica Federal de Rio Grande do Norte (1968-1985)}

\section{RESUMEN}

En el campo educativo, la ideología de la dictadura, a través de la Doctrina de Seguridad Nacional, fue un mecanismo de legitimación de gobiernos militares repercutiendo en reformas en todos los niveles y modalidades. En el caso de la Educación Profesional, hubo cambios en el plan de estudios y acentuación en la rutina escolar, de reglas, horarios y disciplina; así como un fuerte enfoque al modelo técnico- empresarial. El objetivo deeste artículo es discutir la perspectiva teórica sobre la historia oral y la memoria relacionada con la cultura escolar en la Escuela Técnica Federal de Rio Grande do Norte (ETFRN), en1968-1985, durante la Dictadura Militar em Brasil. En este trabajo se destacan las aportaciones de Maurice Halbwachs, Michael Pollack y Ecléia Bosi sobre la noción de memoria, olvido y silencio. Para el tema dede la historia oral se discuten las obras deVerena Alberti, Sebe Bom Meihy y Suzana Ribeiro, Alessandro Portelli, Ana Maria Mauad, quienes constituyen la la base para entender los usos de la historia oral como elun arte de escuchar en loe nuevos tempos, así como generar registros no solo auditivos, sino también visuales. En suma, este trabajo destaca la importância que tiene la oralidade y las fuentes escritas escritas y visuales recopiladas a través de periódicos de la época, fotografías, diarios de clase, currículum, entre otros.Creemos que no existe una realidad unívoca; la misma escuela que reguló y disciplinó fue la que, a través de múltiples experiencias, construyó sujetos críticos capaces de ir más allá de saber hacer. 
Palabras clave: Historia oral. La memoria. La dictadura militar. Doctrina de Seguridade Nacional. Brasil

\section{INTRODUÇÃO}

Neste artigo nos propomos a elucidar o liame entre História e Memória, a partir da compreensão de que a memória dá visibilidade ao objeto, enquanto a história se ocupa em dar inteligibilidade, ambas atuam na construção de narrativas sobre o passado a partir das vozes do presente.

Esse diálogo entre passado e presente ocorre em uma relação longe da neutralidade que tão ingenuamente buscava-se conservar na historiografia antecedente ao século XIX. Isso se deve a natureza do ato de lembrar, que funciona como uma seleção de imagens mentais que não se comprometem com a restituição integral do passado, afinal isso é impossível. A busca por essas lembranças vem carregada de novos significados a tais imagens, a partir de novas significações, crenças e valores que já tenhamos construído no momento da narração.

No que concerne as produções historiográficas acerca do período compreendido entre 1964 e 1985 no Brasil, muitas são as narrativas já produzidas, existe uma gama de trabalhos que se utilizam das mais variadas fontes históricas e métodos. O nosso objetivo aqui é analisar as consequências da Doutrina de Segurança Nacional no contexto da cultura escolar da Escola Técnica Federal do Rio Grande do Norte (ETFRN), tendo por recorte o ano de 1968, ano de sua fundação, e 1985, ano em que convencionalmente os historiadores remetem ao término da Ditadura ${ }^{3}$.

A ETFRN surgiu em meio a um "projeto modernizador" da Educação brasileira, sob forte influência norte-americana, as ações dos governos ditatoriais, especialmente após a promulgação do Ato Institucional n5 pelo presidente Arthur Costa e Silva, sinalizavam para a consolidação da ideologia da ditadura, reverberando em uma série de reformas e

\footnotetext{
3 A historiografia da educação profissional registra estudos sobre as Escolas Técnicas anteriores a este período de análise, a exemplo do trabalho de Silva e Miki (2019).
} 
normatizações nos vários níveis de Ensino. Reformar, modernizar e buscar eficiência eram palavras de ordem na legislação educacional do período, essa modernização autoritária, primava por um ensino mais eficiente e produtivo para o capital, para tanto o país recebia por meio dos Acordos Mec-Usaid uma série de incentivos financeiros, embora ao mesmo tempo, por meio dos Inquéritos Policiais-Militares (IPMs), ocorressem uma série de expurgos, prisões e perseguições a estudantes e professores ${ }^{4}$.

Essas ações irão se legitimar por meio da Reforma Universitária, Lei $n^{\circ}$ 5540/1968 e da Reforma da Educação Básica, Lei 5.692/19715. As quais estavam diretamente ligadas ao Ato Institucional $n^{\circ} 5$ de dezembro de 1968 , considerado o mais duro golpe da Ditadura, posto que, dava plenos poderes aos presidentes militares e permitia a suspensão de quaisquer garantias constitucionais que eventualmente resultaram na institucionalização da tortura, comumente usada como instrumento de legitimação do poder autoritário. Durante a Ditadura, a profissão do técnico industrial foi regulamentada com o objetivo de formar mão-de-obra que suprisse as mais novas indústrias, no contexto do denominado Milagre Brasileiro.

O preâmbulo de nossa pesquisa é o silêncio acerca de possíveis processos punitivos e práticas doutrinadoras dentro da ETFRN, em contrapartida já tivemos a produção de relatórios das Comissões da verdade no Estado tanto na Universidade Federal do Rio Grande do Norte, quanto na Universidade Estadual. Nos deparamos a priori com a limitada quantidade de fontes documentais no arquivo do então Instituto Federal do Rio Grande do Norté, por isso a importância de identificarmos as interfaces

\footnotetext{
${ }_{4}^{4}$ Para compreender melhor a relação ditadura e perseguição no âmbito educacional e a concepção de modernização conservadora, sugerimos a leitura da obra: MOTTA, Rodrigo Patto Sá. As universidades e o regime militar: cultura política brasileira e modernização autoritária. led. Rio de Janeiro: Zahar, 2014.

5 Sobre a legislação educacional no contexto da Ditadura Militar no Brasil ver: Souza (2019) e Lima, Silva e Medeiros Neta (2019).

6 O atual Instituto Federal do Rio Grande do Norte passou por várias nomenclaturas ao longo dos anos. Em 1909, foi Criada a Escola de Aprendizes Artífices, depois em 1937, como Liceu Industrial de Natal, 1942, Escola Industrial de Natal, 1965, Escola Industrial Federal do Rio Grande do Norte, passando em 1968 à Escola Técnica Federal do Rio Grande do Norte
} 
entre os personagens sociais envolvidos na cultura escolar da instituição e os mais remotos vestígios desse passado.

Advertimos sobre importância do Portal da Memória ${ }^{7}$ para 0 embasamento inicial de nossa pesquisa, publicado em 2009 com o objetivo de exaltar o centenário do instituto, esse museu virtual compila fontes orais, escritas e documentais ligadas a escola. As entrevistas orais disponíveis no portal apontam para elementos fundamentais para memória da ETFRN, sobretudo no que concerne ao caráter disciplinador da cultura dessa escola.

Para efeito da organização do artigo, discorremos no primeiro momento sobre a relação história oral e memória como suportes para a escrita da história, oportunamente ponderamos sobre a atualidade dos debates acerca dos usos da história oral na pesquisa histórica. Na segunda parte do trabalho, apresentamos os paradoxos do cenário político social e seus reflexos no âmbito educacional, com foco na história da ETFRN.

\section{ESCRITA DA HISTÓRIA, MEMÓRIA E ORALIDADE}

A arte da memória remonta ao mundo grego antigo e estava diretamente ligada a oratória, ela sobreviveu ao longo do tempo ora com destaque, ora em processo de inferiorização. Durante o século XVII a memória participou ativamente da construção do método científico (YATES, 2007) e foi na década de 1980 que ela desabrochou com um alter ego mais evidente. A esse respeito assim afirmou François Hartog (2013, p. 25),

\footnotetext{
Memória tornou-se, em todo caso, o termo mais abrangente: uma categoria meta-histórica, por vezes teológica. Pretendeu-se fazer memória de tudo e, no duelo entre memória e a história, deu-se rapidamente vantagem à primeira, representada por este personagem, que se tornou central em nosso espaço público: a testemunha [...].
}

(ETFRN), em 1999, a Centro Federal de Educação Profissional e Tecnológica (CEFET-RN), até o atual Instituto Federal de Educação, Ciência e Tecnologia (IFRN), em 2008.

7 O Portal da Memória do IFRN encontra-se disponível em: http://centenario.ifrn.edu.br/ 
A História e seus métodos assumem a centralidade dessa pesquisa que parte do pressuposto da memória como fenômeno não só biológico e psicológico, mas sobretudo, social, sendo essencial para a conservação de certas informações e, por isso, partícipe da História. Pensar a memória exige uma compreensão para além das categorias espaciais, é preciso entendê-la em seus termos psíquicos. Os quais perpassam por um processo argumentativo pragmático, em que ocorre reflexão sobre as formas de se usar a linguagem para representar determinadas memórias e, nesse caso, inevitavelmente o narrador inventa, desmancha, constrói e reconstrói sentidos.

Para a ciência histórica isso não se torna empecilho, visto que a historiografia, atualmente, também se debruça sobre o não dito, o falsificado e o negado, problemática que atinge qualquer tipo de fonte histórica seja material ou imaterial, escrita ou oral. As fontes não são detentoras naturais da verdade histórica, "Pensar o tempo significa, portanto, a obrigação de pensar na linguagem que o diz e que 'nele' se diz [...]" (GAGNEBIN, 2005, p. 73). Daí porque Michel de Certeau (2008) adverte quanto a análise do lugar de fala dos sujeitos e, obviamente de quem produz os materiais que venham a servir como vestígio do passado.

Dando continuidade a abordagem da memória como um fenômeno humano, voltemos as mnemotécnicas gregas. Frances Yates (2007) explica os três princípios gerais da mnemônica: elaboração de uma série de lugares, seleção de imagens e ordenação lógica. Para os gregos um bom orador era um sujeito que conseguisse realizar uma disposição ordenada, o sentido da visão era tido como o mais forte. Segundo Yates, há dois tipos de memória, uma natural e uma artificial, essa última requer treinamento, pois ela se fundamenta em lugares e imagens, que são signos distintivos, símbolos do que queremos lembrar.

Essa memória artificial entraria no escopo do que Maurice Halbwachs (1990) denomina de memória coletiva, na qual algumas lembranças reais se juntam a uma massa compacta de lembranças fictícias. Essas podem ser construídas a partir do compartilhamento de signos e imagens de outros 
agentes sociais, que ao participarem de um mesmo tempo histórico, colaboram para a ressignificação de nossa memória individual. Portanto, depoimentos de outras pessoas corrigem e reorientam nossas lembranças.

Certamente, se nossa impressão pode apoiar-se não somente sobre nossa lembrança, mas também sobre os outros, nossa confiança na exatidão de nossa evocação será maior, como se uma mesma experiência fosse recomeçada, não somente pela mesma pessoa, mas por várias (HALBWACHS, 1990, p. 25).

Para dialogarmos com Maurice Halbawachs precisamos situa-lo historicamente, ele é herdeiro da tradição da sociologia francesa, prolonga os estudos de Émile Durkheim que analisa a precedência do fato social e do sistema social sobre os fenômenos psicológicos e individuais.

Nesse trabalho utilizamos a concepção de memória como fenômeno social, pois o "[...] simples fato de lembrar o passado, no presente, exclui a identidade entre as imagens de um e de outro, e propõe a sua diferença em termos de ponto de vista" (BOSI, 1994, p. 55). Dito de outro modo, a menor alteração do ambiente modifica a imagem íntima da memória, por isso Maurice Halbawchs amarra a memória individual ao grupo e, consequentemente, à tradição.

Convergindo com essa perspectiva, Michel Pollack (1992) ressalta a ligação entre a memória e as identidades sociais, sobretudo quando se trata da história oral. Nesse sentido, para além das funções psicológicas apresentadas anteriormente, coexistem elementos relacionados a acontecimentos vividos pessoalmente e vividos por "tabela", seria uma espécie de memória herdada, projeções ou transferências de memórias. Poderíamos exemplificar com o fato de que pouco lembramos da nossa primeira infância, fase em que os sujeitos não possuem uma definição clara de seu lugar dentro do organismo social.

No geral, temos lembranças herdadas dos parentes mais próximos que ao repetirem narrativas, associadas a objetos e fotografias de nosso passado mais longínquo, nos permitem fazer uma construção artificial da memória. A 
ação de comunicar lembranças organiza e socializa a memória. Assim, entendemos que

\begin{abstract}
O instrumento decisivamente socializador da memória é a linguagem. Ela reduz, unifica e aproxima no mesmo espaço histórico e cultural a imagem do sonho, a imagem lembrada e as imagens da vigília atual. [...] De resto, as imagens do sonho não são, embora pareçam, criações puramente individuais. São representações, ou símbolos, sugeridos pelas situações vividas em grupo pelo sonhador: cuidados, desejos, tensões... "As noções gerais permanecem em nosso espírito durante o sono, nós continuamos a fazer uso delas, a senti-las ao nosso alcance". No quadro dessas "noções gerais", que não abandonam o homem, sequer no sonho, destacam-se as relações de espaço [...], as relações de tempo [...], as relações de causa e consequência [...]. As categorias, que a linguagem atualiza, acompanha nossa vida psíquica tanto na vigília quanto no sonho. $\mathrm{Na}$ vigília, de modo coeso; no sonho, de modo frouxo e amortecido, mas identificável. As convenções verbais produzidas em sociedade constituem o quadro ao mesmo tempo mais elementar e mais estável da memória coletiva (BOSI, 1994, p. 56).
\end{abstract}

Ao colocar a linguagem como o elemento mais estável da memória coletiva, Bosi sinaliza para a importância da sistematização dessa memória, colaborando para evitar a amnésia, problema, que em termos comparativos não atinge somente $O$ indivíduo, mas também a memória coletiva, ocasionando perturbações graves de identidade (LE GOFF, 2003, p. 421), isto posto, precisamos trazer à discussão os impactos da Doutrina de Segurança Nacional na ETFRN.

Pela natureza própria da Ditadura Militar no Brasil tivemos décadas de silenciamento, os personagens envolvidos lidam com uma memória traumática, que em alguns casos acarretaram esquecimento, ou simplesmente o medo de expressar os fatos. Michel Pollack (1989) traz à tona essas inquietações, acrescentando a noção de memória em disputa e colocando a história oral como uma abordagem que reivindica outros espaços na produção das memórias.

Aplicada à memória coletiva, essa abordagem irá se interessar, portanto pelos processos e atores que intervém no trabalho de constituição e de formalização das memórias. Ao privilegiar a análise dos excluídos, dos marginalizados e das minorias, a história oral ressaltou a importância de memórias subterrâneas que, como parte integrante das culturas minoritárias e dominadas, se opõem à "Memória oficial", no caso a memória nacional. [...] essas memórias 
subterrâneas que prosseguem seu trabalho de subversão no silêncio e de maneira quase imperceptível afloram em momentos de crise em sobressaltos bruscos e exacerbados [...] (POLLACK, 1989, p. 4).

O não dito, geralmente tem uma conotação política. "[...] Os esquecimentos e os silêncios da história são reveladores destes mecanismos de manipulação da memória coletiva" (LE GOFF, 2003, p. 422). A história oral é uma metodologia que trabalha com pessoas e, portanto, deve levar em consideração as intersubjetividades que são inerentes, no caso de nosso objeto por muito tempo se manteve em silêncio os acontecimentos relacionados a ETFRN e a Ditadura. Associado a oralidade usaremos também outras fontes: escritas e visuais, sabemos que enfrentaremos dificuldades em encontrar documentações escritas que nos permitam compreender o nosso objeto, em função disso faremos uso dos mais remotos indícios, em jornais da época, fotografias, diários de classe, currículo e etc.

Apoiamo-nos na concepção de documento desenvolvida pela revolução dos Annales na qual são identificadas três fases. A primeira, de 1920 a 1945, sob a orientação de Lucier Febvre e Marc Bloch. A segunda, de 1945 a 1968, sob forte influência de Fernand Braudel e a última, a partir de 1968 chegando aos dias atuais, momento de um ou de alguns pesquisadores. Nesta $3^{a}$ fase é forte $O$ caráter multidisciplinar e interdisciplinar.

A partir da terceira geração dos Annales (final do século XX) houve uma renovação dos temas, problemáticas e procedimentos da pesquisa histórica. Durante o século XIX e início do XX, o termo fonte significava a ideia de testemunho escrito, de prova sobre os acontecimentos do passado. Acreditava-se que a fonte (documento escrito) mantinha uma relação direta com o real. Além disso, nem todo o texto era considerado documento, somente os oficiais eram considerados dignos. Ao longo do século XX, as fontes (documentos) passaram a ser tudo o que é registrado por escrito, por meio de sons, imagens ou que deixou indícios de modos de fazer, de viver e de pensar dos homens. 
Na segunda metade do século XX, após a Segunda Guerra Mundial, os pesquisadores passaram a conceder espaço maior aos métodos qualitativos de investigação científica, "[...] O recurso do gravador portátil, a partir dos anos 1960, permitia 'congelar' o depoimento, possibilitando sua consulta e avaliação em qualquer tempo [...]. As entrevistas passaram a ter estatuto de documento [...]" (ALBERTI, 2005, p. 19). Essa nova forma de documentação histórica exigia a compreensão do depoimento como uma versão do passado, que é apreendido e interpretado de diferentes maneiras.

Uma das inovações da história oral é o conceito de co-colaboração, que imprime uma perspectiva mais humanizadora à prática. O entrevistador prima por uma postura profissional e ética, que não quer dizer neutra ou distante. Usamos o princípio da interação conceituado por Meihy e Ribeiro (2011 , p. 23) em que "[...] a colaboração não iguala as partes, mas convida a um trabalho participante em que os dois polos - os entrevistados e os entrevistadores - são sujeitos ativos, unidos por um propósito de produzir um resultado que demanda conivência". Nessa concepção o entrevistador colabora com a construção do discurso, principalmente no processo de passagem do oral para o escrito, momento em que, também com base em Meihy e Ribeiro (2011) o relato passa pela transcrição, textualização e transcriação8.

Após a passagem do oral para o escrito o discurso ganha contornos de documento, mas é importante sempre considerar que em nenhuma situação de transcrição poderemos transpor todas as emoções e sinais que durante a situação entrevistada somos capazes de captar. Tais especificidades podem aparecer nas análises do trabalho, mas nunca seria possível sua representação na linguagem escrita, mesmo em uma transcrição literal.

Como qualquer outro campo da pesquisa, a história oral hoje passa por processos de adequações ao tempo presente, além da noção de cocriação e novas possibilidades da passagem do oral para o escrito temos

\footnotetext{
8 É importante nesse caso que se faça a leitura da obra "Guia Prático de História Oral" de José Carlos Sebe B. Meihy e Suzana L. Salgado Ribeiro.
} 
também uma era midiática, rica em comunicação em massa e excessivamente imagética. Que tem possibilitado aos historiadores produzirem outros tipos de suporte para suas pesquisas, um deles é a história gráfica e/ou documentários.

Ana Maria Mauad (2016), organizadora do livro "História Oral e mídia: memórias em movimento", questiona: é possivel uma história com imagens? A resposta é que não se trata só do campo da possibilidade, mas da necessidade. Desde os anos 1980 que já circulavam trabalhos de caráter histórico audiovisual ou história gráfica, que trata da incorporação ao campo dos estudos históricos das técnicas de sons e imagens.

Essa nova possibilidade de suporte técnico que os historiadores orais têm abraçado, possibilita uma versão mais acessível dos resultados da pesquisa. Isso implica em lidarmos diretamente com a arriscada ideia de verdade que atinge o imaginário das pessoas quanto à memória e ao mesmo tempo com a maior interferência na produção do discurso, haja vista a presença de equipamentos e pessoal de apoio necessários à filmagem.

Por outro lado, a presença de todo o aparato técnico pode funcionar como catalizador, uma espécie de estimulante psicanalítico que levem os entrevistados a agir com mais clareza e honestidade (MAUAD, 2016, p. 36). Esta nova abordagem requer ainda mais rigor no trabalho do historiador que se aventura com a história oral em sua conexão com a cine-história.

Assumimos os depoimentos como uma co-criação entre entrevistados e entrevistador, "[...] A história oral, então, é primordialmente uma arte da escuta" (PORTELLI, 2016, p. 10). A produção da entrevista como um documento perpassa não somente pela articulação das perguntas feitas pelo historiador, mas pela atmosfera de troca de olhares, respeito e cooperação.

Focaremos não somente no evento, mas na relação que se estabelece entre o lugar e o significado do evento dentro da vida dos narradores. Em um primeiro contato com entrevistas disponíveis no portal da memória da instituição, ficou evidente como a história da instituição se mistura a vida dos personagens de modo quase simbiótico. Há que se levar 
em consideração o conjunto de relações que a história oral implica, segundo Alessandro Portelli (2016) o diálogo, a memória, a História e as histórias, a oralidade da fonte e a escrita do historiador.

\title{
A DOUTRINA DE SEGURANÇA NACIONAL E A ETFRN (1968-1985)
}

Nos idos de 2006 se iniciou o projeto "A caminho do centenário" que objetivava organizar um repositório de memória e história do que atualmente é o IFRN. A compilação das fontes se encontra no Portal da Memória, finalizado em 20099 (ano do centenário), nele podemos encontrar fotografias, documentação oficial (termos, decretos), entrevistas orais gravadas em vídeo, depoimentos escritos, biografia de ex-diretores, entre outros.

O acesso a essas fontes possibilita o direcionamento de variadas pesquisas, embora, como identificou Souza e Medeiros Neta (2016, p. 104)

\begin{abstract}
Apesar do esforço institucional em 'resgatar' a sua memória, guardando-a para as gerações presentes e as do futuro, esse trabalho de arquivamento apresentou alguns problemas com que diz respeito à rigorosidade metodológica que deve assumir um pesquisador: recortes de jornais escaneados e com poucas condições de leitura, ausência de datas nas gravações dos relatos orais, fotografias sem datas, sem legenda e sem autoria.
\end{abstract}

A despeito de tais limitações, o portal constitui um lugar de memória, criando assim representações sobre o passado da instituição, e obviamente a construção dessas representações não foi neutra, atendeu, portanto, a interesses e finalidades específicas, tanto no que foi mostrado como no que foi ocultado. A memória da ETFRN é um espaço novo e ainda cheio de lacunas, por isso, iniciamos o percurso de sua trajetória analisando o contexto político e social interno e externo.

Acerca do contexto político externo, a América Latina sofreu um processo de expansionismo militarista na década de 1970, no caso brasileiro, a ação dos militares na República se deu desde a sua proclamação, mas foi

\footnotetext{
9 https://centenario.ifrn.edu.br/
} 
em 1964 que se inaugurou no país um modelo ditatorial em que os militares eram os próprios condutores do Estado, um intervencionismo que se legitimou pelo hábito e pelo mergulho na Doutrina de Segurança Nacional, que acarretou em um caráter coercitivo e ideológico do regime.

A Doutrina de Segurança Nacional foi criada pelos norte-americanos durante a Guerra Fria, tentando impedir a expansão do comunismo pelo mundo. Após esse momento, perdurou a noção de segurança coletiva e o conflito ideológico como fundamento para eliminação dos fatores adversos que perturbassem a ordem, ideologia inspiradora para as ditaduras que se consolidavam nas américas. Os militares brasileiros, e em seguida os governos militares, tiveram uma aproximação singular com os fundamentos da Doutrina, em função da presença norte-americana em Natal durante a II Guerra Mundial e a ida de muitos militares brasileiros para centros de formação nos EUA (BORGES, 2007).

A disseminação se articulava desde a criação da Escola Superior de Guerra em 1949, a qual possibilitou o surgimento de órgãos como o Sistema Nacional de Informação (SNI), o Centro de Informação do Exército (Ciex) e o Centro de Informação da Aeronáutica (Cisa), no final da década de 1960 , unindo-se ao Centro de Informação da Marinha (Cenimar) já existente. Assim, o aparelho ideológico do Estado se fortalecia e se disseminava.

Na prática, a Doutrina, através de seus conceitos, princípios e fundamentos, permeou, durante os governos militares, toda a estrutura do poder público brasileiro, introduzindo-se, inclusive na escola, quando passaram a ser obrigatórias, em todos os graus do sistema educacional, disciplinas como Moral e Cívica, Organização Social e Política do Brasil e Estudos de Problemas Brasileiros, cujos conteúdos eram formulados tomando por base princípios e conceitos de segurança nacional. Excrecências como essas objetivavam criar uma mentalidade nos estudantes, com toda a força ideológica, no sentido de transformá-los em reprodutores da Doutrina (BORGES, 2007, p. 38).

O cenário da Guerra Fria colaborou para que a Agência Norteamericana de Desenvolvimento Nacional (USAID) fizesse diversas intervenções na política educacional brasileira. A lógica era de modernizar o país para atender as demandas do mercado, em um contexto de nacional 
desenvolvimentismo. John Kennedy, então presidente dos Estados Unidos, havia implantado a Aliança para o Progresso, que era um projeto de ajuda econômica para os países da América Latina e consequentemente preparava o terreno para disseminação dos ideais capitalistas em detrimento ao avanço do comunismo. A escola seria o espaço ideal para moldar a cabeça da juventude.

No início da década de 1960, firmaram-se diversos acordos entre o Ministério da Educação (MEC) e a USAID, algumas das articulações foram: 26 de junho de 1964, Acordo MEC-USAID para aperfeiçoamento do Ensino Primário, 31 de março de 1965, Acordo MEC-Contap (Conselho de Cooperação Técnica da Aliança para o Progresso)-USAID para melhoria do Ensino Médio, 24 de junho de 1966, Acordo MEC-Contap-USAID de assessoria para expansão e aperfeiçoamento do quadro de professores de ensino médio e proposta de reformulação das faculdades de Filosofia do Brasil, 30 de junho de 1966, Acordo MEC-USAID de assessoria para modernização da administração universitária. Além disso foi criada a Comissão BrasileiroAmericana de Educação Industrial (CBAl), que recrutou ex-alunos da Escola Industrial de Natal para enviar ao Paraná, onde receberiam um curso de formação de professores para atuarem na área da indústria. "O convite consistia numa estadia de 10 meses na capital paranaense, com bolsa de estudo, para cursar Magistério em Artes Industriais, ministrado por professores e técnicos brasileiros e norteamericanos [...]" (MEDEIROS, 2011, p. 77).

A iniciativa repercutiu na introdução do método TWI (Training Within Industry) nas escolas industriais brasileiras. Esse método consistia em adaptar os princípios do taylorismo ao ambiente escolar. Na prática educativa a supremacia dos processos de ensino e aprendizagem pautados na repetição e memorização, testes e disciplinamento caracterizaram a cultura escolar da ETFRN.

Um exemplo do papel cumprido pela CBAI na difusão dos princípios de racionalização científica entre os professores do ensino industrial brasileiro pode ser constatado nas recomendações feitas pelo técnico norte-americano, Walter Jones, na obra "Problemas de educação industrial", publicada no Brasil em 1947: "Saliente perante 
seus alunos o fato de que na indústria, via de regra, não se tolera falta de ordem e indisciplina [...] Estabeleça limites máximos de tempo para cada tarefa. [...] É tão importante conseguir a frequência dos alunos quanto obter rapidez na produção. [...] $O$ padrão máximo a desejar deve ser tão alto quanto o que a indústria requer. $O$ instrutor deve estar em dia com os requisitos exigidos para o trabalho industrial, para que possa preparar seus alunos segundo os padrões convenientes. [...] Quando for oportuno e hábil, explore a rivalidade e o espírito de competição entre os alunos. Faça com que eles procurem melhorar os seus recordes" (MEDEIROS, 2011, p. 79).

A aproximação entre o universo fabril e a cultura escolar é latente nos termos usados na citação acima. A ordem, o disciplinamento, a competitividade e a rapidez na produção. Obviamente que associada a essas ações houve um investimento financeiro, que também adivinha dos EUA, por meio de empréstimos.

Na acepção das teorias da modernização elaboradas por cientistas sociais americanos e encapadas pelo governo dos Estados Unidos, principalmente na gestão de Kennedy, a melhor maneira d evencer - desafio revolucionário era modernizar os países 'atrasado's, considerados presas fáceis do inimigo comunista. E a educação era um dos setores prioritários da pauta modernizadora, por seus efeitos multiplicadores e por incutir valores aos jovens [...] (MOTTA, 2014, p. 10).

É nesse cenário que a ETFRN é criada, em junho de 1968, já no novo prédio da Avenida Senador Salgado Filho e com todo 0 aparato ideológico/educacional implantado pelos acordos MEC-USAID, sobretudo no que tange a formação dos professores por meio da CBAl.

A necessidade da conjuntura político/econômica da Ditadura no Brasil (1964-1985) sinalizou para a formação compulsória de técnicos em função do industrialismo crescente, o ensino técnico passa a ser de $2^{\circ}$ grau (atual ensino médio) com um caráter de terminalidade para a formação de $2^{\circ}$ grau, isto é, uma habilitação profissional ${ }^{10}$. Segundo Cunha (2005), os currículos dos cursos técnicos eram compostos por três partes: disciplinas de

10 A relação educação e trabalho no Brasil remete a colonização, emergindo juntamente com a dualidade educacional: formação profissional/formação propedêutica, Cunha (2005) sinaliza o ensino de ofícios destinado aos escravos e uma formação mais conceitual para as classes favorecidas, o saber fazer era o cerne da formação para o trabalho. 
cultura geral, disciplinas de cultura técnica e estágio, tendo como foco a aprendizagem prática da profissão.

Após a deflagração do golpe, o movimento estudantil foi silenciado no âmbito nacional e local, ao mesmo tempo em que diversas Universidades tiveram seus reitores, alunos e professores cassados. Especificamente na ETFRN assim indica Pegado:

O clima político dentro da Instituição, mesmo que em menor escala, comparando-se com outras repartições públicas, sofria reflexos dos embates políticos entre oposição e governo com seus instrumentos de luta e repressão. Muitos alunos e professores sofreram investigações militares. Colegas eram chamados para depor sobre as atitudes suspeitas de determinado professor. Discursos mais inflamados contra o regime eram passíveis de prisão, como ocorreu com o prof. João Faustino. Além dele, muitos professores foram interrogados em inquéritos militares (PEGADO, 2010, p. 43).

Esse movimento era denominado de limpeza ideológica e atingiu principalmente as instituições de ensino superior, no entanto há indícios dessa perseguição também no âmbito das escolas federais e de educação básica. Foram instalados no Brasil em torno de 760 Inquéritos Policial-Militares (IMP) só no ano de 1964. Por isso, Motta (2014) denomina o processo de "crescimento" do Brasil como modernização conservadora, as frentes governamentais almejavam um país de primeiro mundo, para isso implementavam reformas nos diversos níveis educacionais, ao mesmo tempo em que perseguia e prendia seus intelectuais.

Dentro da ETFRN, o estudante Luiz Gonzaga, anteriormente envolvido no movimento estudantil, lançou o jornal Evolução que era datilografado e fixado em cartolinas pelos corredores da escola, muitas vezes esse jornal era rasgado ou pichado, justamente por possuir teor neointegralista. Em 1966 , Luiz Gonzaga aceita a sugestão de se tornar presidente do Centro LíteroRecreativo Nilo Peçanha, tendo sido apoiado pelo então inspetor de alunos.

Sob o lema 'Deus, pátria e família', a gestão de Luiz Gonzaga Cortez à frente do Centro Lítero-Recreativo Nilo Peçanha fora marcada pela publicação dos dois jornais citados, que traziam, como epíteto, a expressão 'porta-voz dos alunos da Escola Industrial'. A primeira edição saíra em junho de 66, com quatro páginas, e a segunda, em setembro, num total de oito páginas, com textos de vários 
colaboradores, entre eles, José Ginane de Medeiros, Jurandir Bezerra de Oliveira, Rubens de Azevedo Maia e José Gilson de Oliveira. Em seu editorial, o 'Manda Brasa' deixava bem claras as pretensões dos redatores: '[...] prometemos lutar em defesa dos nossos interesses, pela revolução democrática de 31 de março, pela democracia e a nossa fé cristã e jamais dormiremos na luta contra o comunismo ateu, internacional e totalitário' (MEDEIROS, 2011, p. 104).

Os princípios da Doutrina de Segurança Nacional revelam-se na narrativa dos responsáveis pelo jornal. Há explicitamente a exaltação à pátria e aos valores de uma sociedade conservadora, a versão do Golpe de 1964 como sendo uma revolução democrática que prometia evitar a disseminação do comunismo, que contrariamente era ateu, internacional e autoritário.

Embora as ações de Luiz Gonzaga estivessem em sintonia com o projeto de doutrinação do governo, outros estudantes que compunham a direção do Centro Lítero-Recreativo Nilo Peçanha, desagradavam a gestão. Em 1967, Luiz Gonzaga foi expulso da escola. Antes mesmo de começar a vigorar o Decreto-lei $n^{\circ} 477 / 69$, que disciplinava alunos, professores e funcionários das instituições públicas e privadas de ensino, sofriam sanções e penalidades aqueles que subvertessem a ordem instaurada pela Ditadura.

Durante a década de 1960 o movimento estudantil dispunha de várias organizações representativas: os DCEs (Diretórios Centrais Estudantis), as UEEs (Uniões Estaduais dos Estudantes) e a UNE (União Nacional dos Estudantes), entre outras. A ação dos estudantes influenciava significativamente os rumos da política nacional, assim que o golpe foi deflagrado em 1964, o movimento foi solapado. A partir daí há um processo de reordenamento, o movimento continuou existindo na ilegalidade, tornando-se uma das principais forças de resistência aos governos ditatoriais nos primeiros anos de recessão. O cenário de maior atuação foi na cidade do Rio de Janeiro, onde ocorriam passeatas, manifestações, pichações, ocupações de prédios públicos, etc.

Em 1968 emergiu uma série de manifestações lideradas pelos estudantes em resistência à Ditadura. No Rio de janeiro, o estudante Edson Luiz morre em confronto com a polícia miliar, causando comoção nacional. No Rio Grande do Norte, os estudantes da ETFRN mobilizaram uma greve na 
tentativa de participarem de uma missa, na antiga Catedral, em memória ao aluno morto no Rio de Janeiro. As manifestações seguiram nos primeiros meses de 1968 no Rio, repercutindo na,

[...] "Semana Sangrenta", como foi nomeada a sequência dos dias 19, 20 e 21 de junho de 1968, foi decisiva para a mudança dos rumos da oposição ao regime militar brasileiro. Em virtude da grande violência policial sobre os estudantes e da ampla cobertura da imprensa, a sociedade civil passou a contestar de forma mais veemente a ditadura que se instalara desde 1964. Logo após a "Sexta-feira Sangrenta", dia de maior violência nas ruas durante o período militar, uma grande mobilização foi articulada pelos estudantes e intelectuais como resposta ao que estava acontecendo. Almejavam uma grande passeata, na qual a sociedade pudesse expor pacificamente seu desejo de democracia. Também não interessava ao governo que conflitos como os da semana anterior se repetissem, pois a cada incidente sua popularidade junto à classe média diminuía. Entretanto, a linha dura do regime via nesses episódios a oportunidade de ampliação do modelo repressivo, e até propôs a decretação do estado de sítio, o que não foi aceito pelo presidente Costa e Silva, mas que, posteriormente, teria influência na criação do Ato Institucional $n^{\circ} 5$ (SIQUEIRA, 2014, p. 392-393).

O Al5 representou o principal instrumento de repressão, pois possibilitava o fechamento do Congresso Nacional, suspensão dos direitos de quaisquer cidadãos, cassação de mandatos eletivos, demissões, entre outras possibilidades. Outra medida foi a inserção obrigatória das disciplinas Educação Moral e Cívica-EMC, Organização Social e Política Brasileira-OSPB e Estudos de Problemas Brasileiros. A EMC visava o culto à Pátria, seus símbolos e tradições.

Na ETFRN foi implantado o momento cívico em 1969, com hasteamento da bandeira e entoação do Hino Nacional no primeiro momento da manhã todas as segundas-feiras. Segundo Medeiros (2011), a professora Anaíde Dantas, já havia sido convocada para depor duas vezes nos IMPs, por sua aproximação com o prefeito Djalma Maranhão na "Campanha de Pé no Chão também se aprende a ler", ela foi convidada a ministrar a disciplina OSPB e assim relatou essa experiência:

É claro que eu não podia me soltar, por causa que a gente tinha que seguir a disciplina do MEC. Mas eles (os alunos) forçavam a gente. Queriam que a gente dissesse alguma coisa. Só que a gente não 
podia dizer. [...] A gente seguia o livro OSPB, Organização Social e Política, dali não podia passar, mesmo que não concordasse. A gente não concordava, ultimamente não concordava, mas o negócio era grosso. E ninguém queria perder o emprego (DANTAS apud MEDEIROS, 2011, p. 107).

O depoimento da professora Anaíde Dantas corrobora para pensarmos as tensões entre os desmandos do governo e a liberdade de expressão e autonomia didática dos docentes, além das relações com os estudantes que também se dividiam entre opositores e defensores da ditadura.

Tais embates criavam um clima de vigilância e disciplinamento constantes na ETFRN, ainda pouco discutido pela academia, especialmente no que tange as vozes dos personagens envolvidos. Além de indicar as tensões quanto a construção das representações da memória desse período, para tanto, reunir estes sujeitos e dar-Ihes a oportunidade de fala evitará a amnésia social sobre este período da história da instituição.

\section{CONSIDERAÇÕES FINAIS}

Ao assumirmos o desafio de trabalhar com a memória da Ditadura Militar e seus impactos na ETFRN, entendíamos que seria um exercício minucioso de análise das fontes documentais, imagéticas e depoimentos. Nossa pesquisa ainda, em desenvolvimento, aponta para os efeitos da Doutrina de Segurança Nacional em vários âmbitos da escola, desde o currículo até o cotidiano das atividades.

Há indícios de perseguição e prisão de professores, funcionários e estudantes, envolvidos no processo de resistência à ditadura, iremos a partir de agora entrar em contato com esses agentes sociais e realizarmos as entrevistas. Tendo como pressuposto as concepções de memória e história, entendemos a importância que o discurso dos sujeitos tem para a construção da representação do passado e para a ressignificação das memórias individuais que por vezes podem estar difusas. Como afirmamos, anteriormente, a linguagem é o elemento mais estável da memória coletiva, 
nesse sentido o nosso trabalho colabora para a monumentalização da memória da ETFRN.

\section{REFERÊNCIAS}

ALBERTI, V. Manual de história oral. 3. ed. Rio de janeiro: Editora FGV, 2005.

BORGES, N. A Doutrina de Segurança Nacional e os governos militares. In: FERREIRA, J.; DELGADO, L. A. N. (orgs.). O Brasil republicano - o tempo da ditadura: regime militar e movimentos sociais em fins do século XX. 2. ed. Rio de Janeiro: Civilização Brasileira, 2007. p. 13-42.

BOSI, E. Memória e sociedade: lembranças de velhos. São Paulo: Companhia das Letras, 1994.

BRASIL. Decreto $n^{\circ} .477$ de 26 de fevereiro de 1969. Define infrações disciplinares praticadas por professores, alunos, funcionários ou empregados de estabelecimentos de ensino público ou particulares, e dá outras providências. Disponível em: <http://www2.camara.leg.br/legin/fed/declei/1960-1969/decreto-lei-477-26fevereiro-1969-367006-publicacaooriginal-1-pe.html>. Acesso em: 08 jan 2020.

CERTEAU, M. A escrita da história. Trad. Maria de Lourdes Menezes. 2 ed. Rio de Janeiro: Forense Universitária, 2008.

CUNHA, L. A. O ensino de ofícios nos primórdios da industrialização. 2. ed. São Paulo: UNESP; Brasília: FLACSO, 2005.

DANTAS, A. Anaíde Dantas: Sobre a Escola Industrial de Natal. Entrevistador: Arilene Lucena de Medeiros. Natal, 01 jul. 2010. 1 gravação digital audiovisual em minidv. (35min). In: MEDEIROS, A. L. A forja e a pena: técnica e humanismo na trajetória da Escola de Aprendizes Artífices de Natal à Escola Técnica Federal do Rio Grande do Norte. Natal: IFRN, 2011.

GAGNEBIN, J. M. Dizer o Tempo. In: Sete aulas sobre linguagem, memória e história. 2. ed. Rio de Janeiro: Imago, 2005. p. 67-78.

HALBWACHS, M. Memória coletiva e memória individual. In: HALBWACHS, M. Memória coletiva. São Paulo: Editora Vértice, 1990, p. 25-43.

HARTOG, F. Regimes de historicidade: presenteísmo e experiências do tempo. Belo Horizonte: Autêntica, 2013.

LE GOFF, J. História e memória. 5. ed. Campinas, SP: Unicamp, 2003.

LIMA, A. C. S.; SILVA, F. R. M.; MEDEIROS NETA, O. M. Uso de documentos na pesquisa histórica: uma análise da legislação educacional nos anos de chumbo (1964-1985). Perspectivas e Diálogos: Revista de História Social e Práticas de Ensino, v. 1, n. 3, 2019. Disponível em: 
<http://www.revistas.uneb.br/index.php/nhipe/article/download/6549/4181>. Acesso em: 08 jan 2020.

MAUAD, A. M. (org.). História oral e mídia: memórias em movimento. São Paulo: Letra e Voz, 2016.

MEDEIROS, A. L. A forja e a pena: técnica e humanismo na trajetória da Escola de Aprendizes Artífices de Natal à Escola Técnica Federal do Rio Grande do Norte. Natal: IFRN, 2011.

MEIHY, J. C. S. B.; RIBEIRO, S. L. S. R. Guia prático de história oral: para empresas, universidades, comunidades, famílias. São Paulo: Contexto, 2011.

MOTTA, R. P. S. As universidades e o regime militar: cultura política brasileira e modernização autoritária. Rio de janeiro: Zahar, 2014.

PEGADO, E. A. C. A trajetória do CEFET-RN desde a sua criação no início do século XX ao alvorecer do século XXI. $2^{a}$ ed. Natal: IFRN, 2010.

POLLAK, M. Memória e Identidade Social. Revista de estudos históricos, Rio de Janeiro, 1992, v. 5, n. 10, p. 200-212.

POLLAK, M. Memória, esquecimento e silêncio. Revista de estudos históricos, Rio de Janeiro, 1989, vol. 2, n. 3, p. 3-15.

PORTELLI, A. História oral como arte da escuta. São Paulo: Letra e Voz, 2016.

SILVA, V. R.; MIKI, P. S. R. Escola Técnica de Manaus (ETM) à Escola Técnica Federal do Amazonas (ETFAM) - (1942-1965): uma perspectiva histórica.

Revista Exitus - ISSN 2237-9460, [S. I.], v. 9, n. 4, p. 805 - 831, 2019. DOI:

10.24065/2237-9460.2019v9n4ID1034. Disponível em:

<http://www.ufopa.edu.br/portaldeperiodicos/index.php/revistaexitus/article /view/1034>. Acesso em: 10 jan 2020.

SIQUEIRA, M. N. A era dos estudantes: Rio de Janeiro, 1964-1968. Revista do arquivo geral da cidade do Rio de Janeiro. Rio de Janeiro, 2014, n. 8, p.379397.

SOUZA, F. C. S. Educadores brasileiros e o despertar de aptidões. History of Education in Latin America - HistELA, v. 2, p. e 16506, 24 mar. 2019. Disponível em: <https://periodicos.ufrn.br/histela/article/view/16506>. Acesso em: 15 jan 2020.

SOUZA, F. C. S.; MEDEIROS NETA, O. M. O portal da memória do IFRN como fonte de pesquisa em História da Educação Profissional. In: MOURA, Dante Henrique. Educação profissional: desafios teórico-metodológicos e políticas públicas. Natal, IFRN, 2016, p. 101-117.

YATES, F. A. A arte da memória. Campinas: Unicamp. 2007. 
Recebido em: 27 de julho de 2020 Aprovado em: 16 de setembro de 2020 Publicado em: 18 de novembro de 2020

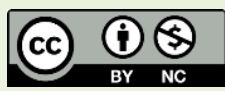

